\title{
Prevalence of erosive wear lesions in Gastro- Esophageal Reflux Disease patients - A case series
}

www.adum.edu.my

Ann Dent UM 2021, 28: 1-7

Dol: 10.22452/adum.vol28no1

\author{
Prema Sukumaran $^{1 *}$, Divya Nambiar ${ }^{2}$, Siti Nurshakina Abdul Kamar ${ }^{1}$, Nur Azwa Nadia M \\ Zalani $^{1}$, Rathna Devi Vaithilingam ${ }^{1}$, Goh Khean Lee ${ }^{3}$
}

KEYWORDS

GERD, tooth wear, BEWE, prevalence

\begin{abstract}
Extra esophageal manifestation of Gastro-esophageal reflux disease (GERD) include erosive wear dental lesions. Early erosive wear lesions in this group of patients can be easily missed as they are accompanied by few clinical signs and hardly any symptoms. This case series aims to report the prevalence and severity of erosive wear lesions amongst a sample of GERD patients in Malaysia. Eleven subjects with well characterized GERD, diagnosed based on modified Reflux Disease Questionnaire (RDQ) or via endoscopy, were included in this case series. A standardized intra oral clinical examination was performed to assess presence and severity of erosive wear lesions on tooth surfaces using Basic Erosive Wear Examination (BEWE) index. Majority of BEWE score 1 lesions were distributed in maxillary anterior teeth, followed by maxillary posterior and mandibular teeth. BEWE score 2 lesions were most prevalent in maxillary anterior teeth and there were no BEWE score 3 lesions observed. Based on the clinical findings, more erosive wear lesions were found on the buccal surfaces of maxillary and mandibular teeth in GERD patients. This case series further confirms the link between GERD and erosive wear lesions. The authors would like to highlight the need for both medical and dental practitioners to be aware of early clinical presentations of GERD and erosive wear lesions. Early diagnoses allow for intervention and conservative management of these conditions.
\end{abstract}

\section{INTRODUCTION}

Gastro-esophageal reflux disease (GERD) is defined as involuntary muscle relaxing of the lower esophageal sphincter, allowing refluxed gastric acid and its contents to move upward through esophagus into the oral cavity (Mitre and Katzka, 2004). A putative link has been established between Gastro-esophageal Reflux Disease (GERD)

\footnotetext{
${ }^{1}$ Department of Restorative Dentistry, Faculty of Dentistry, University of Malaya, Kuala Lumpur 50603, Malaysia ${ }^{2}$ Private Practice, Seri Kembangan, Selangor 43300, Malaysia. ${ }^{3}$ Faculty of Medicine, University of Malaya, Kuala Lumpur 50603, Malaysia

*Correspondence: prema@um.edu.my
}

and dental erosive wear lesions and this association was also documented as an atypical manifestation of GERD in addition to cough, laryngitis and asthma (Vakil et al., 2006). The first clinical case of association between dental erosive wear lesions and reflux was reported by Bargen and Austin in 1937 in a medical case report of a woman who had chronic vomiting (Bargen and Austin, 1937). In their report, the authors had recognized the potential for refluxed acid to cause erosion or damage to teeth.

Reflux erosive wear lesion is caused by the regurgitation of stomach acid into the mouth. The regurgitated acid has a $\mathrm{pH}$ of approximately 1-3.5, which is significantly lower than the critical 
threshold for dental hard tissue dissolution ( $\mathrm{pH} 5.5)$ (Wild et al., 2011). Thus, the repeated exposure of acid from these gastric contents into the oral cavity has the potential to erode enamel and dentin, which are the first and second layers of dental hard tissues, leading to erosive wear lesions (Sujatha et al., 2016). Table 1 lists typical and atypical clinical manifestation of GERD (Chandra et al., 2004).

Table 1: Typical and atypical clinical manifestation of GERD

Typical clinical manifestation

Oesophageal Heartburn, regurgitation,
belching, bloating, dysphagia, nausea, oesophagitis, stricture, Barrett's oesophagus, adenocarcinoma

\begin{tabular}{ll}
\hline & Atypical clinical manifestation \\
\hline Cardiac & Chest pain, sino-atrial block \\
\hline Pulmonary & $\begin{array}{l}\text { Chronic cough, asthma, micro- } \\
\text { aspiration, pneumonia }\end{array}$ \\
\hline Otorhinolaryn & $\begin{array}{l}\text { Hoarseness, dysphonia, vocal } \\
\text { gology } \\
\text { stenosis, globus, pharyngitis, } \\
\text { laryngitis, laryngeal carcinoma, } \\
\text { altered taste, earache, otitis } \\
\text { media }\end{array}$ \\
\hline Dental & Erosive wear lesions \\
\hline
\end{tabular}

There has been marked paucity of published literature on the association of erosive wear lesions and GERD. However, a recent similar study in China observed erosive wear lesions in $60.8 \%$ of the 51 GERD patients who were clinically examined. This study reported that participants with GERD were more likely to have erosive wear lesions. The same study also showed a correlation between consumption of carbonated drinks and GERD and erosive wear lesions (Li et al., 2017).

Severity of erosive wear lesions can be objectively quantified using the validated Basic Erosive Wear Examination (BEWE) scoring system, (Bartlett et al., 2008) although it has been established that both detailed history and thorough clinical examination is essential to diagnose these lesions. The BEWE system was designed to be a simple, reproducible and transferable scoring system for recording clinical findings and for assisting in the decisionmaking process for the management of erosive tooth wear (Bartlett et al., 2008). Both medical and dental practitioners should be aware that a thorough clinical examination as well as detailed history taking are important to diagnose the presence of erosive wear lesions, especially lesions at the initial stage with BEWE score 1. It is often very easy to miss the intraoral clinical presentations of these lesions if the clinical findings are not related to medical history. Also, the early erosive wear lesions can be easily missed as it is accompanied by few clinical signs and rarely any symptoms (Bartlett et al., 2008).

Historically, GERD was uncommon in the Asian region. Kang and colleagues were first to report on GERD in Asians in 1993 (Kang et al, 1993). 3.3\% of the 11943 patients surveyed were reported to have reflux esophagitis (RE). A study by Chang et al (1997) from Taiwan reported a prevalence of $5 \%$ of RE in 2044 healthy patients who came for routine esophagogastroduodenoscopy (EGD).

In 2005, a systematic review reported an approximate prevalence of GERD of $10-20 \%$ in Europe and the USA, and of less than 5\% in Asia (Dent et al., 2005). In 2014, El-Serag and co-authors (two of whom were contributors in the initial study) published a follow-up review assessing the epidemiology of GERD in the same regions as the previous study as well as in Middle East. They reported the lowest range of prevalence estimates was in East Asia (2.5-7.8\%) while the higher ranges of prevalence estimates were in North America (18.1-27.8\%), Europe (8.8-25.9\%) and Middle East (8.7-33.1\%) (El-Serag et al., 2014). Between the two systematic reviews, only East Asia showed prevalence estimates consistently lower than $10 \%$. The authors concluded that despite the increasing prevalence of GERD worldwide, it does show a considerable geographic variation.

In Malaysia, in 1998, Ho et al reported the prevalence of GERD at $1.6 \%$ in an initial survey, and in a follow-up study in 2011 reported an increase in prevalence to $10.6 \%$ (Ho et al., 1998; Ho, 2011). In another study, Rosaida and Goh examined 1000 patients prospectively and reported that $38.8 \%$ of these patients were diagnosed as having GERD based on either predominant symptom of heartburn and acid regurgitation and/or findings of RE. Apart from GERD, this study also reported on the prevalence of RE (13.4\%) and non-erosive reflux disease (NERD) (65.5\%) (Rosaida and Goh, 2004). More recent studies have also shown an increase in the prevalence of GERD in Asian population in the past two decades although the figures vary based on the method of diagnosis (Goh et al., 2014; ElSerag et al., 2014; Ho, 2011). 
To date, apart from the study by Li and colleagues in China, there is no reported data on the prevalence and severity of erosive wear lesions amongst GERD patients in the Asian region in general and Malaysia in particular. Hence, this case series documents the association of GERD and erosive wear lesions, particularly the prevalence and severity, in a sample of GERD patients in Malaysia. We hope this case series will pave way for a more robust longitudinal study to investigate the progression of erosive wear lesions in association with GERD, diet and other confounding factors such as oral $\mathrm{pH}$ and dietary habits.

\section{CLINICAL CASE SERIES}

Consecutive patients seen within a span of three months who were diagnosed with GERD were recruited for the compilation of this case series which had the approval of the Research and Ethics Committee of the Faculty of Dentistry, University of Malaya [DF RD1513/0043(U)]. Patients were diagnosed based on the modified Reflux Disease Questionnaire RDQ (Nik et al., 2011) or when they had well characterized reflux esophagitis at endoscopy. Eleven patients were included based on pre-determined inclusion criteria as follows: (a) no underlying systemic medical disease such as cardiac disease, (b) minimum 20 teeth present intra orally, (c) age between 20-55 years old, (d) able to attend dental appointments and, (e) able to provide informed consent. Patients were excluded if they (a) were undergoing orthodontic treatment, (b) had an eating disorder such as anorexia nervosa, (c) gastric disorders such as peptic ulcer, and (d) on medication which may contribute to xerostomia. Patients who were recruited to be a part of this clinical case series had consented to having an intraoral examination performed on them. A standardized intraoral examination was performed by one calibrated examiner to assess presence and severity of erosive wear lesions. Kappa score of 0.71 and 0.76 was reported for inter and intra examiner reliability respectively which indicates 'substantial' reproducibility. Tooth surfaces were cleaned to remove residual plaque before they were examined intra orally using a dental probe and compressed air under good dental lighting. In each subject, the (a) buccal, (b) occlusal, and (c) palatal/lingual surfaces of all permanent teeth present (except third permanent molars) were examined and scored using BEWE index as defined earlier shown in Table 2 (Bartlett et al.,2008).

Teeth with carious lesions and restorations involving more than $50 \%$ of the surface assessed and missing teeth were excluded from the scoring.
Lingual surfaces of mandibular teeth were not assessed for presence of erosive wear lesions as these surfaces are protected by the salivary flow as well as the resting position of tongue, which offers a physical barrier against acid reflux. Additionally, incisal surfaces of maxillary and mandibular anterior teeth were also not included in the assessment and scoring as these surfaces are more prone to attrition compared to erosive wear lesions (Lussi and Jaeggi, 2008). Tooth wear observed on the incisal surfaces of anterior teeth are usually a combination of attrition and erosion with attrition being the predominant contributor.

Table 2: Validated BEWE index used for the scoring of erosive wear lesions (Adapted from Bartlett et al., 2008)

\begin{tabular}{cl}
$\begin{array}{c}\text { BEWE } \\
\text { Score }\end{array}$ & Definition \\
\hline 0 & No surface loss \\
\hline 1 & Initial loss of surface texture \\
\hline 2 & $\begin{array}{l}\text { Distinct defect, hard tissue loss }<50 \% \\
\text { of the surface area }\end{array}$ \\
\hline 3 & $\begin{array}{l}\text { Hard tissue loss } \geq 50 \% \text { of the surface } \\
\text { area }\end{array}$ \\
\hline
\end{tabular}

\section{CLINICAL FINDINGS}

A total of 704 teeth in 11 subjects were scored using the BEWE index. BEWE score 0 was the most prevalent on the buccal and occlusal surfaces while BEWE score 1 was more prevalent on the buccal surfaces (Table 3).

Table 3: Distribution of erosive wear lesions in buccal, palatal and occlusal surfaces

\begin{tabular}{ccccc}
$\begin{array}{c}\text { BEWE } \\
\text { score }\end{array}$ & Buccal & Palatal & Occlusal & Total \\
\hline 0 & 143 & 48 & 103 & 294 \\
\hline 1 & 100 & 62 & 48 & 210 \\
\hline 2 & 3 & 9 & 8 & 20 \\
\hline 3 & 0 & 0 & 0 & 0 \\
\hline$* x / 9$ & 62 & 35 & 83 & 180 \\
\hline Total & 308 & 154 & 242 & 704 \\
\hline
\end{tabular}

*Teeth which were missing and surfaces which could not be scored for reasons explained in the section above 
The highest score of erosive wear lesions recorded was BEWE score 2 which were primarily distributed in the palatal surfaces as shown in Table 3. 180 teeth could not be scored as they were either missing or had presence of caries and/or restorations on the surface examined. BEWE scores 1 and 2 lesions were most prevalent in maxillary anterior teeth while score 0 was largely distributed on the mandibular teeth (Table 4). There were no score 3 lesions observed for all teeth examined. It should be noted that figures in Table 4 were tabulated based on surfaces examined for each category of dentition as shown in Table 5. As described in the previous section, some surfaces of teeth were not examined as they are rendered physiological protection by saliva or because they were more prone to attrition than erosion.

Table 4: Prevalence of BEWE scores in maxillary and mandibular teeth based on surfaces scored

\begin{tabular}{cccc}
\hline BEWE score & $\mathrm{A}^{\mathrm{a}}$ & $\mathrm{B}^{\mathrm{a}}$ & $\mathrm{C}^{\mathrm{a}}$ \\
\hline 0 & $33.3 \%$ & $37.5 \%$ & $49.4 \%$ \\
\hline 2 & $46.2 \%$ & $26.5 \%$ & $25.7 \%$ \\
\hline 3 & $6.1 \%$ & $1.5 \%$ & $2.6 \%$ \\
\hline$*_{\mathrm{x} / 9}$ & 0 & 0 & 0 \\
\hline Total & $14.4 \%$ & $34.9 \%$ & $22.4 \%$ \\
\hline
\end{tabular}

*Teeth which were missing and surfaces which could not be scored for reasons explained in the section above

${ }^{\mathrm{a}} \mathrm{A}=$ Maxillary anterior teeth; $\mathrm{B}=$ Maxillary posterior teeth; $\mathrm{C}=$ Mandibular teeth

Table 5: Surfaces examined for each category of teeth

\begin{tabular}{cc}
\hline Teeth & Surfaces examined \\
\hline $\begin{array}{c}\text { Maxillary } \\
\text { anterior teeth }\end{array}$ & Buccal, Palatal \\
\hline $\begin{array}{c}\text { Maxillary } \\
\text { posterior teeth }\end{array}$ & Buccal, Palatal, Occlusal \\
\hline $\begin{array}{c}\text { Mandibular } \\
\text { teeth }\end{array}$ & Buccal, Occlusal \\
\hline
\end{tabular}

\section{DISCUSSION}

This case series recorded presence of erosive wear lesions on 230 out of the 704 teeth examined, with a prevalence of $31.0 \%$, in patients diagnosed with GERD. In 2018, Ab Halim and co-workers, reported
45.0\% prevalence of erosive tooth wear in 16-year old adolescence, with no history of GERD, in Kuantan Malaysia (Ab Halim et al, 2018). Erosive wear lesions in GERD patients are most prevalent on buccal and palatal surfaces of maxillary teeth, as these surfaces are exposed to the regurgitated acid and not protected by tongue or other structures. A similar trend is observed in this case series with a prevalence of $32.5 \%$ and $40.3 \%$ of erosive wear lesions on the buccal and palatal surfaces respectively, as seen in Table 3. Table 4 also shows that erosive wear lesions in this sample of patients are more prevalent on the maxillary teeth. On the contrary, in a sample of subjects with no history of GERD, these lesions are more prevalent in the posterior mandibular teeth whilst the maxillary and mandibular anterior teeth are least affected ( $A b$ Halim et al, 2018). However, in GERD patients, buccal surfaces of the mandibular teeth can be affected as the acid tends to pool in the mandibular buccal sulcus (Holbrook et al., 2009).

Figure $1 \mathrm{~A}$ shows an example of BEWE score 1 on the occlusal surface of the upper right second premolar while Figure $1 \mathrm{~B}$ shows score 2 on the palatal surfaces of the upper right lateral incisor and canine. BEWE score 3 erosive wear lesions can be seen on the palatal surfaces of the upper central incisors in Figure 1C.

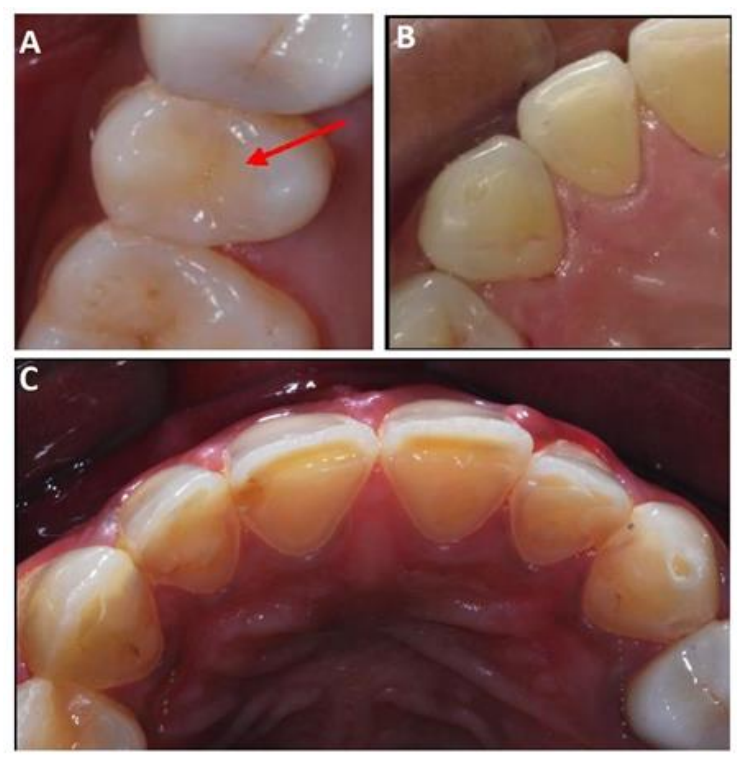

Figure 1. Examples of BEWE scores. (A) BEWE score 1 on the occlusal surfaces of the upper right second premolar (indicated with arrow). (B) BEWE score 2 on the palatal surfaces of the upper right lateral incisor and canine. (C) BEWE score 3 erosive wear lesions on the palatal surfaces of the upper right and left central incisors

Erosive wear lesions often progress slowly and go unnoticed in the early stages. In many cases, 
patients complain of sensitivity to cold or hot stimulation during eating or drinking. This clinical symptom is due to exposed dentinal tubules as a result of the loss of enamel (Johansson et al., 2008). Clinical features of erosive wear lesions include yellowish discoloration of the teeth, cupping out of occlusal surfaces leading to exposed dentine and broad concave lesions on enamel and dentine surfaces (Wild et al., 2011). In anterior teeth, these lesions may present with an increased incisal translucency, incisal thinning, chipping and cupping out of the incisal edges as seen in Figure 2 (Chandra et al., 2004; Sujatha et al., 2016). Shiny wear facets on tooth structure or restorations may also be observed (Lussi and Jaeggi, 2008). Commonly, erosive wear lesions advance quickly in dentine when other types of tooth wear such as attrition and abrasion become superimposed on these lesions (Addy \& Shellis, 2006). Lesions found on the palatal surfaces of maxillary molars, buccal surfaces of mandibular molars and palatal surfaces of maxillary anterior teeth strongly suggest a pattern of erosion caused by gastric acid (Holbrook et al., 2009).

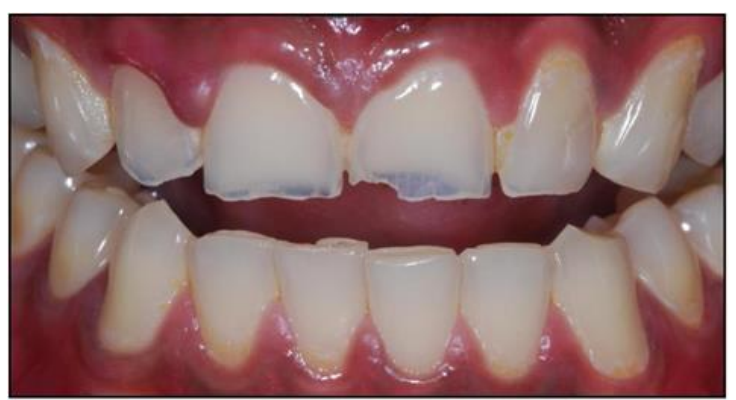

Figure 2. Clinical presentation of erosive wear lesions involving upper anterior teeth

In patients who do not present with GERD related symptoms, the erosive wear lesions are present primarily on the occlusal surfaces of teeth. This pattern of distribution indicates the source of acid is more extrinsic in nature from consumption of acidic food and beverages. Studies have shown strong association between the pattern of erosive wear lesions and consumption of acidic beverage especially among young adults. One study particularly describes erosion of the incisors as closely linked to the pattern of consumption of acidic carbonated drinks (Moazzez et al., 2000). However, the quantity, quality and buffering capacity of saliva are confounding factors, together with the variation in enamel solubility at different sites intraorally and between patients (Johansson et al., 2002). Clinically, it is difficult to differentiate between erosive wear lesions arising from intrinsic or extrinsic acid. Arguably, the diagnosis is often made based on the symptoms presented by patients and dietary habits, in addition to clinical findings.

Although this case series affords evidence of presence of erosive wear lesions amongst this sample of GERD patients, the severity of lesions only ranges between scores 1 and 2 . From a dental practitioner's stand point, this is favorable as the management of these lesions would include monitoring and conservative management such as placement of anti-hypersensitivity agent or restorative material for lesions which have progressed into dentine. In patients with BEWE scores of 2 and 3 , complex treatment may be necessary, encompassing re-organizing the occlusion with full mouth rehabilitation of the dentition.

The case series shows none of the 11 patients had a score 3 . The authors acknowledge the small sample size as a limiting factor. However, the clinical cases presented show the amount of acid regurgitated into the oral cavity could determine the severity of erosive wear lesions. Sonnenberg wrote that gastric output correlates with body size and therefore men have higher gastric acid output than women (Sonnenberg, 2011). Drawing parallelism from this observation, the authors feel that gastric acid output in the western population is higher compared to Asian population and this could potentially explain the absence of BEWE score 3 lesions in this sample. This could be attributed to the bigger physical make-up of the western population compared to the Asian population.

Raising awareness on the presence and early detection of erosive wear lesions amongst GERD patients and gastroenterologist or physicians is vital in preventing these lesions from progressing. A dentist maybe the first to detect signs of GERD in a patient if erosive wear lesions are present in the oral cavity. Likewise, it would be useful if a medical practitioner is able to detect presence of erosive wear lesions in GERD patients based on history and symptoms.

\section{CONCLUSION}

The prevalence of erosive wear lesions in this sample of patients is $31.0 \%$. BEWE score 1 and 2 lesions were most prevalent in maxillary anterior teeth and no score 3 lesions were present in this sample of patients. It is imperative for both medical and dental clinicians to identify the signs and symptoms of GERD and erosive wear lesions as early recognition of these lesions will allow the condition to be managed conservatively and successfully. 


\section{ACKNOWLEDGEMENT}

The authors would like to thank our medical colleagues, support staff and postgraduate student at the Gastrointestinal Unit, University Malaya Medical Centre (UMMC), Malaysia for all help rendered in the data acquisition and patient management. This study was funded in full by University of Malaya's Bantuan Kecil Penyelidikan
(BKP) research grant. Grant number/project code: [BK015-2015].

\section{DECLARATION OF INTEREST}

The authors of this article certify that they have no proprietary, financial, or other personal interest of any nature or kind in any product, service, and/or company that is presented in this article.

\section{REFERENCES}

1. Ab Halim N, Esa R, Chew HP. General and erosive tooth wear of 16-year-old adolescents in Kuantan, Malaysia: prevalence and association with dental caries. BMC Oral Health. 2018;18(1):11-18. DOI: 10.1186/s12903-017-0451-9.

2. Addy M, Shellis RP. Interaction between attrition, abrasion and erosion in tooth wear. Monogr Oral Sci. 2006;20:17-31. DOI: 10.1159/000093348.

3. Bargen JA, Austin LT. Decalcification of teeth as a result of obstipation with long continued vomiting: Report of a case. J Am Dent Assoc. 1937;24: 1271.

4. Bartlett D, Ganss C, Lussi A. Basic Erosive Wear Examination (BEWE): a new scoring system for scientific and clinical needs. Clin Oral Investig. 2008;12 (Suppl 1) S65-68.

5. Chandra A, Moazzez R, Bartlett D, Anggiansah A, Owen WJ. A review of the atypical manifestations of gastroesophageal reflux disease. Int J Clin Pract. 2004;58(1):41-48.

6. Chang CS, Poon SK, Lien HC, Chen GH. The incidence of reflux esophagitis among the Chinese. Am J Gastroenterol. 1997;92:668-671.

7. Dent J, El-Serag HB, Wallander MA et al. Epidemiology of gastro-oesophageal reflux disease: a systematic review. Gut. 2005; 54:710-717.

8. Goh KL, Choi MG, Hsu WPI, Chun HJ, Mahachai V, Kachintorn U, Leelakusolvong S, Kim N, Rani AA, Wong BCY, Wu J, Chiu CT, Chu R, Shetty V, Bocobo JC, Chan MM, Lin JT. Unmet treatment needs of gastroesophageal reflux disease in Asia: Gastroesophageal reflux disease in Asia Pacific Survey. J Gastroen Hepatol. 2014;29(12):1969-1975.

9. El-Serag HB, Sweet S, Winchester CC, Dent J. Update on the epidemiology of gastro-oesophageal reflux disease: a systematic review. Gut. 2014;63(6):871-880.

10. Ho KY, Kang JY, Seow A. Prevalence of gastrointestinal symptoms in a multiracial Asian population, with particular reference to reflux-type symptoms. Am. J. Gastroenterol. 1998;93(10):1816-1822.

11. Ho KY. From GERD to Barrett's esophagus: Is the pattern in Asia mirroring that in the West? J Gastroen Hepatol. 2011;26(5):816-824.

12. Holbrook WP, Furuholm J, Gudmundsson K, Theodors A, Muerman JH. Gastric reflux is a significant causative factor of tooth erosion. J. Dent. Res. 2009;88(5):44244-6.

13. Johansson A, Johansson A-K, Omar R, Carlsson GE. Rehabilitation of worn dentition. J Oral Rehabil. 2009; 35(7):548-566.

14. Johansson AK, Lingstrom P, Birkhed, D. Comparison of factors potentially related to the occurence of dental erosion in high- and low-erosion groups. Eur J Oral Sci. 2002;110:204-211. DOI:10.1034/j.16000447.2002.11211.x.

15. Kang JY, Tay HH, Yap I, Guan R, Lim KP, Math MV. Low frequency of endoscopic esophagitis in Asian patients. J Clin Gastroenterol. 1993;16(1):70-73

16. Li W, Liu J, Chen S, Wang Y, Zhang Z. Prevalence of dental erosion among people with gastroesophageal reflux disease in China. J Prosthet Dent, 2017;117(1):48-54.

17. Lussi A, Jaeggi T. Erosion--diagnosis and risk factors. Clin Oral Investig. 2008;12(Suppl 1):S5-13.

18. Mitre MC, Katzka DA. Pathophysiology of GORD: Lower Esophageal Sphincter Defects. Practical Gastroenterology. 2004;44-58.

19. Moazzez R, Smith BGN, Bartlett DW. Oral pH and drinking habit during ingestion of a carbonated drink in a group of adolescents with dental erosion. J Dent. 2000;28(6):395-397.

20. Nik WNNW, Banerjee A, Moazzez R. Gastro-Oesophageal Reflux Disease Symptoms and Tooth Wear in Patients with Sjogren's Syndrome. Caries Res. 2011;45(3):323-326. 
21. Rosaida MS, Goh KL. Gastro-oesophageal reflux disease, reflux oesophagitis and non-erosive reflux disease in a multiracial Asian population: a prospective, endoscopy based study. Eur J Gastroen Hepat. 2004;16(5):495-501.

22. Sonnenberg A. Effects of Environment and Lifestyle on Gastroesophageal Reflux Disease. Digest Dis. 2011;29(2):229-234. DOI: 10.1159/000323927.

23. Sujatha $\mathrm{S}$, Jalihal U, Devi $\mathrm{Y}$, Rakesh $\mathrm{N}$, Chauhan $\mathrm{P}$, Sharma S. Oral pH in gastroesophageal reflux disease. Indian J Gastroenter. 2016;35(3): 186-189.

24. Vakil N, van Zanten SV, Kahrilas P, Dent J, Jones R, and the Global Consensus Group. The Montreal Definition and Classification of Gastroesophageal Reflux Disease: A Global Evidence-Based Consensus. Am J Gastroenterol. 2006;101:1900-1920. DOI:10.1111/j.1572-0241.2006.00630.x.

25. Wild YK, Heyman MB, Vittinghoff E, Dalal DH, Wojcicki JM, Clark AL, Rechmann B, Rechmann P. Gastroesophageal Reflux Is Not Associated With Dental Erosion in Children. Gastroenterology. 2011;141(5):1605-1611.

\section{Editorial History}

Date of Submission: 6 Nov 2020

Review \& Revision: 10 Nov 2020 - 15 Jan 2021

Accepted: 15 Jan 2021

Published: 11 Feb 2021

License Information: This work is licensed under a Creative Commons Attribution 